\title{
COMPARATIVE EVALUATION OF SHEAR BOND STRENGTH OF A BIOACTIVE COMPOSITE AND NANO-COMPOSITE: AN IN VITRO STUDY
}

\author{
Sahar Abd El Halim*
}

\begin{abstract}
Objectives: The aim of this study was to determine and compare the shear bond strength of activa bioactive restorative with and without adhesive and nano-composite.

Materials and Methods: Sixty freshly extracted human premolars were used. The teeth were mounted vertically in a self-cure acrylic cylinder. A high-speed fine diamond disk with copious water spray was used to obtain a flat dentin of the labial surface. One clinician prepared all the teeth. The teeth were divided into three groups twenty teeth each, n=20 Group I : The flat dentin surfaces were acid-etched for $15 \mathrm{sec}$ with $37 \%$ phosphoric acid, it washed and dry then application of bioactive composite into a plastic ring measuring $3 \mathrm{~mm}$ width and $2 \mathrm{~mm}$ depth. Each specimen was light cured for $40 \mathrm{sec}$ by LED light cure unit. Group II: The flat dentin surfaces were acid-etched and then two coats of bonding agent was applied over each specimen and light cured for $20 \mathrm{sec}$. then application of bioactive composite. Group III (Control): The flat dentin surfaces were acid-etched and application of bonding agent then nano-composite applicated into a plastic ring measuring $3 \mathrm{~mm}$ width and $2 \mathrm{~mm}$ depth. Each specimen was light cured for $40 \mathrm{sec}$ by LED light cure unit. All of the specimens were tested for shear bond strength and all of the data were analyzed by One way analysis of variance (ANOVA) and Tukey's post hoc test.
\end{abstract}

Results: Results showed that the highest mean value was detected in Nanocomposite, followed by bioactive composite with adhesive, the mean shear bond strength of Nanocomposite and composite with adhesive was significantly greater than bioactive composite without adhesive $(\mathrm{p}<0.0001)$.

Conclusions: Nanocomposite showed higher shear bond strength followed by bioactive composite with adhesive, while bioactive composite without adhesive showed the lowest shear bond strength value.

* Associate Professor, Operative Dentistry Department, Misr University for Science and Technology, Egypt 


\section{INTRODUCTION}

Composite resin is the most widely used modern dental restorative material. It has advantages such as excellent esthetics and ease of handling. However, it is also characterized by the risk of complications due to incomplete polymerization of the material and the occurrence of polymerization shrinkage.$^{[1]}$ Nanotechnology is the science dealing with the production of substances on a nanometric scale with the particle size ranging from $0.1 \mathrm{~nm}$ to $100 \mathrm{~nm}$. Hence, the properties and the structure of materials can be altered at the nanometer level to bring about dramatic improvements. ${ }^{[2]}$ This technology has applied to develop nanocomposite. [3] In recent years, many efforts have been undertaken to develop restorative composite having physicochemical properties similar to those of the natural tooth structure. Improvements of currently used commercial dental restorative composite resins are focused on the reduction of the polymerization shrinkage as well as improvement of mechanical properties, wear resistance, biocompatibility and processing properties. ${ }^{[4]}$ The replacement of composite resin restorations due to secondary caries at restoration-tooth interface is still one of the greatest problems. The decreased incidence of secondary caries along the margins of composite restorations led to the development of fluoride releasing composite resins. ${ }^{[5,6]}$ One of the primary tasks in dentistry has always been to invent an ideal restorative material which has physical properties similar to those of natural tooth structure, adhesion to dentin and enamel. ${ }^{[7]}$ Bioactive composite provides the strength and esthetics with a shock absorbing resin component that helps the material absorb forces in the mouth. The material also provides improved fluoride release when compared to glass ionomers. It provides optimal marginal seals and can be placed without any additional bonding agents.[8,9] These restorations are durable, fracture and wear resistant, show chemical binding to the teeth, show less microleakage, and help in release and recharge of calcium, phosphate, and fluoride ions. They are free from bisphenol A derivatives. ${ }^{[10,11]}$ The aim of this in vitro study was to determine and compare the shear bond strength of activa bioactive restorative with and without adhesive and nano-composite.

\section{MATERIALS AND METHODS}

Sixty freshly extracted human premolars were used. The selected teeth should not present restorations, caries, fracture or cracks. Teeth were stored in distilled water at room temperature to prevent dehydration. The teeth were mounted vertically in a self-cure acrylic (Rapid Repair, Detrey Dentsply Ltd, Surrey, U.K.) cylinder, the labial surface for each tooth would be parallel to the chisel during debonding when testing for shear bond strength. A high-speed fine diamond disk (Isomet 2000 Precision saw, Buehler USA) with copious water spray was used to obtain a flat dentin of the labial surface. One clinician prepared all the teeth. The teeth were divided into three groups twenty teeth each, $\mathrm{n}=20$ Group I : The flat dentin surfaces were acid-etched for $15 \mathrm{sec}$ with $37 \%$ phosphoric acid (3M/ESPE, St. Paul, MN, USA), washed and dry then application of bioactive composite into a plastic ring measuring $3 \mathrm{~mm}$ width and $2 \mathrm{~mm}$ depth. Each specimen was light cured for $40 \mathrm{sec}$ by LED light cure unit. Group II: The flat dentin surfaces were acid-etched like group I and then two coats of bonding agent (Adper single bond $2^{\mathrm{TM}} 3 \mathrm{M}$ ESPE, Germany) was applied over each specimens and light cured for $20 \mathrm{sec}$. then application of bioactive composite, the same procedure as carried out in the group I. Group III (Control): The flat dentin surfaces were acid-etched and bonding like group II then application of nano-composite (Filtek TM $\mathrm{Z} 350 \mathrm{XT}$ ) into a plastic ring measuring $3 \mathrm{~mm}$ width and $2 \mathrm{~mm}$ depth. Each specimen was light cured for $40 \mathrm{sec}$ by LED light cure unit.

The materials were used in this study, and their compositions are given in Table 1 .

\section{Shear Bond Strength testing}

All of the specimens were then stored in distilled water for $24 \mathrm{hr}$. These tests were performed using Bluehill Lite Software from Instron ${ }^{\circledR}$. 
TABLE (1) The commercial names, compositions and manufacturers of the materials used

\begin{tabular}{|c|c|c|}
\hline Material & Manufacturer & Composition \\
\hline $\begin{array}{l}\text { Bioactive restorative } \\
\text { A2 Shade }\end{array}$ & $\begin{array}{l}\text { Pulpdent Corporation } \\
80 \text { Oakland street. } \\
\text { Watertown,MA,02472.USA }\end{array}$ & $\begin{array}{l}56 \% \text { by weight reactive glass particles that mimic physical and } \\
\text { chemical properties of natural teeth., shock absorbing ionic resin } \\
\text { component containing acidic monomer with antimicrobial proper- } \\
\text { ties. no Bisphenol A, No BisGMA, no BPA derivatives. They are } \\
\text { two-paste, automix systems with three setting mechanisms: light } \\
\text { cure, self-cure resin chemistry, and self-cure glass ionomer reaction. }\end{array}$ \\
\hline $\begin{array}{l}\text { Filtek }^{\mathrm{TM}} \text { Z } 350 \text { XT } \\
\text { A2 Shade }\end{array}$ & $\begin{array}{l}\text { 3M ESPE, St. Paul, MN, } \\
\text { USA }\end{array}$ & $\begin{array}{l}\text { The fillers are a combination of aggregated zirconia/silica cluster } \\
\text { filler with an average cluster particle size of } 0.6 \text { to } 1.4 \text { microns and a } \\
\text { nonagglomerated /non-aggregated } 20 \text {-nm silica filler. Theinorganic } \\
\text { filler loading isapproximately } 78.5 \% \text { by wt ( } 59.5 \% \text { by volume). It } \\
\text { contains bis-GMA, UDMA, TEGDMA, and bis-EMA. }\end{array}$ \\
\hline $\begin{array}{l}\text { Adper }{ }^{\mathrm{TM}} \text { Single Bond } \\
\text { Plus }\end{array}$ & $\begin{array}{l}\text { 3M ESPE } \\
\text { St. Paul, MN 55144-1000 } \\
\text { USA }\end{array}$ & $\begin{array}{l}\text { Vitrebond }{ }^{\mathrm{TM}} \text { Copolymer } \\
\text { - Nanofiller } \\
\text { - Ethanol } \\
\text { - Dimethacrylates } \\
\text { - HEMA } \\
\text { - Water } \\
\text { - Initiators }\end{array}$ \\
\hline
\end{tabular}

\section{Test procedure}

A circular interface shear test was designed to evaluate the bond strength. All samples were individually and horizontally mounted on a computer controlled materials testing machine (Model 3345; Instron Industrial Products, Norwood,MA, USA) with a loadcell of $5 \mathrm{kN}$ and data were recorded using computer software (Bluehill Lite Software from Instron $\left.{ }^{\circledR}\right)$. The acrylic block embedded tooth with its own bonded composite was secured to the lower fixed compartment of testing machine by tightening screws. Shearing test was done by compressive mode of load applied at substrate -resin interface using a mono-bevelled chisel shaped metallic rod attached to the upper movable compartment of testing machine traveling at cross-head speed of $0.5 \mathrm{~mm} / \mathrm{min}$. The load required to debonding was recorded in Newton.

\section{Shear bond strength calculation;}

The load at failure was divided by bonding area to express the bond strength in $\mathrm{MPa}: \tau=\mathrm{P} / \pi \mathrm{r}^{2}$ where ; $\tau=$ shear bond strength (MPa), $\mathrm{P}=$ load at failure $(\mathrm{N}), \pi=3.14$ and $\mathrm{r}=\operatorname{radius}$ of $\operatorname{resin} \operatorname{disc}(\mathrm{mm})$

\section{Statistics analysis}

All of the data were analyzed by One way analysis of variance (ANOVA) and Tukey's post hoc test were used to compare between groups. The significance level was set at $p<0.05$. Statistical analysis was performed with SPSS 16.0 (Statistical Package for Scientific Studies, SPSS, Inc., Chicago, IL, USA) for Windows.

\section{RESULTS}

\section{Shear bond strength}

Results showed that the highest mean value was detected in Nanocomposite, followed by bioactive composite with adhesive, whereas the lowest value was recorded in bioactive composite without adhesive. ANOVA test and Tukey's post hoc test revealed that the mean shear bond strength of Nanocomposite and composite with adhesive was significantly greater than bioactive composite without adhesive $(p<0.0001)$, (Table 2, Fig.1) 
TABLE (2) Comparison of Shear bond strength (MPa) in Nanocomposite and bioactive composite with or without adhesive (ANOVA test)

\begin{tabular}{|c|c|c|c|c|c|c|c|}
\hline \multirow{2}{*}{ Group } & \multirow[b]{2}{*}{ Mean } & \multirow[b]{2}{*}{ Std. Dev } & \multirow[b]{2}{*}{ Std. Error } & \multicolumn{2}{|c|}{$\begin{array}{l}95 \% \text { Confidence Interval } \\
\text { for Mean }\end{array}$} & \multirow[b]{2}{*}{ Min } & \multirow[b]{2}{*}{ Max } \\
\hline & & & & $\begin{array}{l}\text { Lower } \\
\text { Bound }\end{array}$ & $\begin{array}{l}\text { Upper } \\
\text { Bound }\end{array}$ & & \\
\hline Nano Composite & $18.19 \mathrm{a}$ & 3.41 & 0.76 & 16.60 & 19.79 & 11.12 & 27.77 \\
\hline Bioactive Composite with Adhesive & $17.00 \mathrm{a}$ & 4.20 & 0.94 & 15.04 & 18.97 & 11.93 & 26.24 \\
\hline Bioactive Composite without Adhesive & $8.30 \mathrm{~b}$ & 1.34 & 0.30 & 7.67 & 8.93 & 4.94 & 9.88 \\
\hline $\mathrm{F}$ & & & & & & & 56.24 \\
\hline $\mathrm{P}$ & & & & & & & $.0001^{*}$ \\
\hline
\end{tabular}

Significance level $p<0.05$, * significant

Tukey's post hoc test: means sharing the same superscript letter are not significantly different

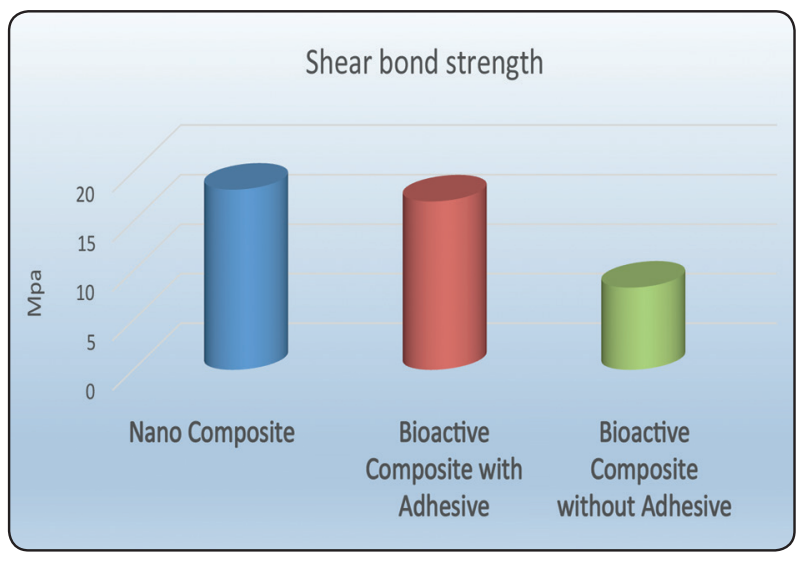

Fig. (1) Column chart showing mean shear bond strength (MPa) in Nanocomposite and bioactive composite with or without adhesive

\section{DISCUSSION}

The current study determined and compared the shear bond strength of activa bioactive restorative with and without adhesive and nano-composite. Different mechanical tests have been proposed to assess the bonding performance of restorative materials. Shear testing has been widely used to evaluate the bonding ability of adhesive materials to dental structure. ${ }^{[12]}$ Shear bond strength test is a simple evaluation procedure used to test the adhesion of dental materials. Thus, in our study shear bond strength testing was done with a universal testing machine, Instron, which is conventionally popular. ${ }^{[13]}$

As regards shear bond strength results from the current study were showed that the highest mean value was detected in Nano-composite, followed by bioactive composite with adhesive, whereas the lowest value was recorded in bioactive composite without adhesive. This finding is in agreement with other studies that showed that the nanorestorative materials exhibited high shear bond strength compared to other type of composite, even when tested with the same adhesive, meaning that the composite formulation also had an impact on bond strength. Materials containing more resin components in their composition may exhibit improved bond strength performance with evidence of mechanical interlocking. ${ }^{[14,15,16]}$ However other studies reported that nanocomposite showed some better performance (higher bond strength) than the other composites as it contains (Bis-EMA) and nanofiller $(5-75 \mathrm{~nm}) \cdot{ }^{[17]}$ Moreover Beun and Singh determined that nanotechnology has a significant contribution in resin composite research. Due to the reduced dimension of particle size and a variable size 
distribution, an increased filler load can be achieved with the consequence of reducing the polymerization shrinkage and improving the mechanical properties such as tensile strength, compressive strength and resistance to fracture. These may be equivalent to or higher than other type of composites.${ }^{[18-19]}$ Moreover filler Improvements in Filtek ${ }^{\mathrm{TM}}$ Z350 nanocomposite, this filler technology was improved. The manufacturing process, where the clusters are formed, was modified to produce less sintering. The resin contains bis-GMA, UDMA, TEGDMA, and bis-EMA resins. The fillers are a combination of non-agglomerated/non-aggregated $20 \mathrm{~nm}$ silica filler, non-agglomerated/non-aggregated 4 to $11 \mathrm{~nm}$ zirconia filler, and aggregated zirconia/silica cluster filler (comprised of $20 \mathrm{~nm}$ silica and 4 to $11 \mathrm{~nm}$ zirconia particles). The nanoclusters are produced in a broad range of sizes enabling a high filler loading. These nanoclusters still have the structural integrity to provide strength, fracture and wear resistance. ${ }^{[20]}$

The current study reported that the highest mean value was detected in Nano-composite, followed by bioactive composite with adhesive. Bioactive materials may be considered as boon to dentistry due to its regeneration potential. It is a composite resin that is bioactive and releases more fluoride than glass ionomers. It contains bioactive resin matrix, a shock absorbing resin component and BAG fillers that have similar properties of tooth. ${ }^{[8]}$ Activa Bioactive products are the first dental resins that mimic the physical and chemical properties of teeth. They contain three key components: Bioactive ionic resin matrix, Shock-absorbing rubberized resin component and reactive ionomer glass fillers. ${ }^{[9]}$ Bioactive composite has the advantages of glass ionomers in a strong, resilient, resin matrix that will not chip or crumble. It chemically bonds to teeth, seals against bacterial microleakage, releases more fluoride, and is more bioactive than glass ionomers, and is more durable and fracture resistant than composites. Activa restorative contains glass particles and polyacid components of resin-modified glass ionomer ce- ments, which undergo the acid/base neutralization hardening reaction of all glass-ionomer systems. In addition, they also contain a bioactive ionic resin matrix, and thereby are able to achieve polymerization by both light cure and chemical cure. ${ }^{[10-21]}$ Thus, there are three hardening mechanisms involved with the Activa restorative, and release and recharge with calcium, phosphate, and more fluoride ions than glass ionomers. In addition, Activa contains no bisphenol A (BPA), bisphenol A glycidyl methacrylate (bis-GMA), or BPA derivatives. ${ }^{[22,23,24]}$ Activia's ionic resin contains phosphate acid groups with antimicrobial properties that improve the interaction between the resin and the reactive glass fillers and enhance the interaction with tooth structure. [25,26] Through an ionization process that is dependent upon water, hydrogen ions break off from the phosphate groups and are replaced by calcium in tooth structure. This ionic interaction binds the resin to the minerals in the tooth, forming a strong resinhydroxyapatite complex and a positive seal against microleakage. $[27,28,29,30]$

The lowest shear bond strength value was recorded in bioactive composite without adhesive. Rai etal, 2017 reported that surface conditioning of dentin resulted in significantly higher bond strength than unconditioned dentin surfaces. The main reason for use an adhesive is to facilitate penetration of composite into etched dentin surface to provide a better bond to tooth structure. Single bond adhesive was found to provide up to $97 \%$ retention rate. ${ }^{[7]}$ Ansari 2004 concluded that decreased shear bond strength for teeth restored with composite after $37 \%$ phosphoric acid etching using no bonding agent occurred due to the incapability of composite to wet the cavity surfaces and its inability to penetrate into the micromechanical irregularities. This can be explained by the fact that composite is highly viscous than bonding agents and doesn't produce hybrid layer, subsequently leading to weak adhesive joint. ${ }^{[31]}$ 


\section{CONCLUSIONS}

Within the limitations of the current study, it could be concluded that:

Nanocomposite showed higher shear bond strength followed by bioactive composite with adhesive, while bioactive composite without adhesive showed the lowest shear bond strength value.

\section{REFERENCE}

1. Colak H, Ercan E,Hamidi MM. Shear bond strength of bulk-fill and nano- restorative materials to dentin. European Journal of Dentistry, 2016,10 (1):40-45.

2. Singh M, Singh N, Saini A, Singh PK, Tewari T and Tandon C. In-vitro Shear Bond Strength of a Nano-composite Resin in Comparison with Microfilled and Microhybrid Composite Resins. British Journal of Medicine \& Medical Research;2017,19(2):1-6

3. Korkmaz Y, Gurgan S, firat E, Nathanson D. Shear bond strength of three different nano-restorative materials to dentin. Oper Dent. 2010;35(1):50-7.

4. Deshmukh S and Nandlal B. Evaluation of the Shear Bond Strength of Nanocomposite on Carious and Sound Deciduous Dentin. Int J Clin Pediatr Dent. 2012; 5(1): 25-28.

5. Swift EJ. Fluoride release from two composite resins. Quintessence International. 1989; 20:895-97.

6. Gupta S, Vellanki VK, Shetty KV, Kushwah S, Goyal G S. Chandra MS. In Vitro Evaluation of Shear Bond Strength of Nanocomposites to Dentin. Journal of Clinical and Diagnostic Research. 2015,9(1): 9-11.

7. Rai N, Naik R, Gupta R, Shetty S, Singh A. Evaluating the Effect of Different Conditioning Agents on the Shear Bond Strength of Resin- Modified Glass Ionomers. Contemporary Clinical Dentistry,2017 ;8 (4): 604-612.

8. Sonarkar S, Purba R. Bioactive materials in conservative dentistry. International Journal of Contemporary Dental and Medical Reviews (2015), Article ID 340115, 4 Pages

9. www.activabioactive.fr/wp.../06/ACTIVA-White-PaperXF-VWP4-REV-6-2016

10. The future of dentistry now in your hands. PULPDENT® publication. Watertown, MA: Pulpdent Corporation; 2014.

11. Alkhudhairy F, Zeeshan H Ahmad. Comparison of Shear
Bond Strength and Microleakage of Various Bulk-fill Bioactive Dentin substitutes: An in vitro Study. The Journal of Contemporary Dental Practice,2016;17(12):997-1002.

12. Poggio C, Beltrami R, Scribante A, Colombo M, Lombardini M. Effects of dentin surface treatments on shear bond strength of glass-ionomer cements. Annali di Stomatologia. 2014;5:15-22.

13. Kerby RE, Knobloch LA, Clelland N, Lilley H, Seghi R. Microtensile bond strengths of one-step and self-etching adhesive systems. Operative Dentistry. 2005;30:195-200.

14. Pereira PN, Yamada T, Inokoshi S, Burrow MF, Sano H \&Tagami J (1998) Adhesion of resin-modified glass ionomer cements using resin bonding systems Journal of Dentistry.1998;26(5-6) 479-485.

15. Carvalho RM, Yoshiyama M, HornerJA \& PashleyDH. Bonding mechanism of VariGlass to dentin American Journal of Dentistry.1995 8(5) 253-258.

16. Korkmaz Y, Gurgan S, Firat E. Nathanson D. Shear Bond Strength of Three Different Nano- Restorative Materials to Dentin. Operative Dentistry, 2010, 35-1, 50-57

17. Beun S, Glorieux T, Devaux J, Vreven J, Leloup G. Characterization of nanofilled compared to universal and microfilled composite. Dent Mater. 2006;16.

18. Farek B, Munksgaards EC, Andreassen JO, Kreiborg S. Fractured teeth bonded with dentin adhesives with and without unfilled resin. Dent Traumatol 2002,18:66-69.

19. Rathore VPS, Hotkar CG, Patel P, Praveen D, Mahankudo G, Jadhav PD. Comparative Evaluation Of Shear Bond Strength Of Microfilled And Nanofilled Composite Resin Cured Under Light Emitting Diode (Led) an in Vitro Study. Ijocr , 2015;3(9):4-7.

20. multimedia.3m.com/mws/media/.../filtek-z350-xt-technical-product-profile.pdf

21. Fluoride release of bioactive restoratives with bonding agents. Murali S, et al. J Dent Res 95 (Spec Iss A): S0368, 2016 (www.iadr.org).

22. Croll TP, Berg JH and Donly KJ. Dental Repair Material: A Resin-Modified Glass-Ionomer Bioactive Ionic ResinBased Composite. Compendium, 2015;36(1)

23. Chen L, Shen H and Suh BI.Bioactive dental restorative materials: A review.American journal of dentistry 2013;26(4):219-27 
24. www.activabioactive.fr/wp.../06/ACTIVA-White-PaperXF-VWP4-REV-6-2016

25. Sharma S, Kugel G, et al. Comparison of antimicrobial properties of sealants and amalgam. IADR Annual Meeting 2008 .

26. Naorungroj $\mathrm{S}$, et al. Antibacterial surface properties of fluoride-containing resin-based sealants. J Dent 2010.

27. Pameijer $\mathrm{CH}$. Microleakage of four experimental resin modified glass ionomer restorative materials. April 2011.

28. Microleakage of dental bulk fill, conventional and self-ad- hesive composites. Cannavo M, et al. J Dent Res 93 (Spec Iss A): 847, 2014.

29. Comparison of mechanical properties of dental restorative material. Girn V, et al. J Dent Res 93 (Spec Iss A): 1163, 2014.

30. Singla R, et al. Comparative evaluation of traditional and self-priming hydrophilic resin. J Conserv Dent 2012;15(3):233-6.

31. Ansari A.A. An evaluation of strength of composite resin restorations using different bonding agents. An in vitro study. J Indian Soc Pedo Prev Dent. 2004;22(4):162-167. 